\title{
Qualitatively and quantitatively similar effects of active and passive maternal tobacco smoke exposure on in utero mutagenesis at the HPRT locus Stephen G Grant*
}

\author{
Address: Department of Environmental and Occupational Health, Graduate School of Public Health, University of Pittsburgh, Pittsburgh, \\ Pennsylvania 15260, USA \\ Email: Stephen G Grant* - sgg@pitt.edu \\ * Corresponding author
}

Published: 29 June 2005

BMC Pediatrics 2005, 5:20 doi:10.1 |86/|47|-243|-5-20
Received: II February 2005

Accepted: 29 June 2005

This article is available from: http://www.biomedcentral.com/I47I-243I/5/20

(c) 2005 Grant; licensee BioMed Central Ltd.

This is an Open Access article distributed under the terms of the Creative Commons Attribution License (http://creativecommons.org/licenses/by/2.0), which permits unrestricted use, distribution, and reproduction in any medium, provided the original work is properly cited.

\begin{abstract}
Background: Induced mutagenesis in utero is likely to have life-long repercussions for the exposed fetus, affecting survival, birth weight and susceptibility to both childhood and adult-onset diseases, such as cancer. In the general population, such exposures are likely to be a consequence of the lifestyle choices of the parents, with exposure to tobacco smoke one of the most pervasive and easily documented. Previous studies attempting to establish a direct link between active smoking and levels of somatic mutation have largely discounted the effects of passive or secondary exposure, and have produced contradictory results.
\end{abstract}

Methods: Data from three studies of possible smoking effects on in utero mutagenesis at the HPRT locus were compiled and reanalyzed, alone and in combination. Where possible, passive exposure to environmental tobacco smoke was considered as a separate category of exposure, rather than being included in the non-smoking controls. Molecular spectra from these studies were reanalyzed after adjustment for reported mutation frequencies from the individual studies and the entire data set.

Results: A series of related studies on mutation at the X-linked HPRT locus in human newborn cord blood samples has led to the novel conclusion that only passive maternal exposure to tobacco mutagens has a significant effect on the developing baby. We performed a pooled analysis of the complete data from these studies, at the levels of both induced mutation frequency and the resulting mutational spectrum.

Conclusion: Our analysis reveals a more commonsensical, yet no less cautionary result: both active maternal smoking and secondary maternal exposure produce quantitatively and qualitatively indistinguishable increases in fetal HPRT mutation. Further, it appears that this effect is not perceptibly ameliorated if the mother adjusts her behavior (i.e. stops smoking) when pregnancy is confirmed, although this conclusion may also be affected by continued passive exposure.

\section{Background}

It has now been unambiguously established that cigarette smoking causes lung and other cancers, and that exposure to secondary tobacco smoke exhaled by smokers also has 
a causal role in carcinogenesis [1,2]. Carcinogenic smoke metabolites act primarily as genotoxicants by direct DNA adduction as well as by producing oxidative DNA damage. These DNA adducts therefore act as effective biological markers of tobacco smoke carcinogen exposure, integrating differences in metabolic capacity that modify the activation of such chemicals in the body. A subset of these adducts elude the cellular DNA repair systems, which also exhibit interindividual functional variation, persisting through DNA replication to produce mutations [reviewed in [3]]. Thus, induced mutations in surrogate reporter genes can also act as biomarkers of tobacco smoke carcinogenesis, although there is an attenuation of the genotoxic "signal". Induced mutagenesis is therefore more a measure of biological effect than a quantification of exposure [4]. The HPRT assay is the most widely applied measure of in vivo mutagenesis and has often been used as an intermediate biomarker of biological effect in exposed populations [5,6]. Although most individual studies and meta-analyses have demonstrated a significant induction of in vivo mutation in smokers [6,7], there are still exceptions [8-10]. Similarly, there are contradictory studies on the effect of maternal smoking on mutation frequencies in their unborn offspring [11,12].

Maternal tobacco smoking has been associated with premature delivery, low birth weight, deficient lung and neurological function, and increased risk of perinatal mortality [3,13-16]. During differentiation and development, specific cell types are sequentially induced to proliferate, when they become hypersensitive to cytotoxic agents, resulting in the observed dependence of teratological effects upon timing of exposure [17]. Although it has not been proven, there is great concern that the developing fetus might also be hypersensitive to genotoxic agents, producing many oncogenically "initiated" cells which might then expand during the fulfillment of the developmental program. Many studies have demonstrated that tobacco carcinogens cross the placenta $[18,19]$, so that their mutagenic effects might be detected in the offspring. Additionally, in the particular case of the HPRT assay, cord blood mutation frequencies $\left(\mathrm{M}_{f}\right)$ measured at birth are approximately 10 -fold lower than that predicted from age-dependence data in older children and adults, with a correspondingly low variance, such that cord blood HPRT mutation measurements should be uniquely sensitive to inductive effects [20].

A number of studies have been undertaken to determine whether maternal "lifestyle" factors influence in utero mutagenesis, often specifically targeting smoking as the putative source of genotoxicants. Indeed, two studies from essentially the same laboratories have come to very different conclusions on this question: first, that there was no detectable effect of maternal tobacco smoke exposure on HPRT $\mathrm{M}_{f}$ in cord blood [21], and second, that despite the fact that there was no increase in the $\mathrm{M}_{f}$ of children born to mothers who had been exposed to environmental tobacco smoke, there was a significant shift in the mutational spectrum in these children, indicating that different mechanisms of mutation were responsible for their observed $\mathrm{M}_{f}[22,23]$. We now report a pooled reanalysis of these data, which provides evidence for a more coherent interpretation of these studies. We find that children of active smokers, women who quit smoking when they found they were pregnant and women who were exposed only to secondary smoke during their pregnancy all had similar, significant increases in T-lymphocyte HPRT $\mathrm{M}_{f}$ over offspring of women who reported neither active nor secondary exposure. These data provide a rationale for a shift in the HPRT mutational spectra in children of mothers passively exposed to environmental tobacco smoke. These data also provide evidence that secondary smoking exposure can have effects indistinguishable from active smoking. This result is discussed in the context of other attempts to document the genotoxic effects of tobacco smoke, and with regard to our own observations in women who attempted to protect their unborn child by quitting smoking during pregnancy.

\section{Methods \\ Data}

All HPRT assays were performed by the method of O'Neill et al [24] in the laboratories of R.J. Albertini, B.A. Finette and colleagues at the University of Vermont. Exposure histories were obtained by questionnaire at postpartum interviews. Women were considered to be passively exposed if they lived or worked in the presence of active smokers. Tobacco carcinogen biomarkers were not specifically determined in the first study [21], although biomarkers of drug abuse were concurrently monitored and corroborated interview data, and in previous studies in the same hospital population serum thiocyanate and cotinine levels corroborated histories of active smoking $[25,26]$. Tobacco smoke exposure in the second study $[22,23]$ was assessed by measurement of cord blood cotinine levels [27]. The authors identified two subjects whose cotinine levels were not in agreement with their self-reported tobacco smoke exposure group (MFS72 from the passive exposure group and MFS30 from the "quitters" both had cotinine levels characteristic of active smokers) and excluded them from subsequent analysis. In addition, subject MFS99 from the actively smoking group had undetectable cotinine levels, and cotinine levels were not performed on MFS9 from the passively exposed group. These data were analyzed three ways, first retaining these samples in their self-reported categories, in keeping with the assignment of the data from Manchester et al [21], second, deleting them from the analysis as per 
Finette et al $[22,23]$, and third, reassigning these samples to the category indicated by their cotinine results.

Data from the study of Manchester et al [21] was obtained by pooling their two data sets identified as "University Hospital Colorado" (tobacco smoke exposure was ascertained in only 60 of the 67 subjects analyzed) and "Private Hospital Colorado". Data from the second study is largely that of Finette et al [22] supplemented with new subjects MFS3, MFS14, MFS36, MFS83 and MFS89 in the nonsmoking, non-passively exposed group, the addition of MFS12 to the passively exposed group (subsequently removed as an outlier), and the adjustment of the $M_{f}$ of MFS65 in the passively exposed group, all reported in Finette et al [23].

Two outliers (defined as having HPRT $\mathrm{M}_{f}$ greater than three standard deviations higher than the population) had been previously identified, one in each of these studies. These values both remained outliers in their respective data sets after ln transformation, but only the highest outlier remained significant after pooling the transformed data from the two studies. Except where specifically mentioned in the text, inclusion or exclusion of these subjects did not affect the statistical analyses performed on these populations.

\section{Statistical analysis}

Pairwise analyses were performed on native and ln transformed data using Student's $t$ test assuming equal variance from the statistical toolpack of Microsoft Excel. Nonparametric analyses were performed using the Mann-Whitney $U$ test available in MiniTab. Except where noted, all three analyses yielded equivalent results regarding significance. Overall smoking effects were evaluated using single factor ANOVA from Excel.

Comparisons of distributions were performed by the chisquare test in MiniTab. Mutations were considered to be independent if they arose uniquely and/or demonstrated a unique rearrangement of the T-cell receptor $\beta$ and $\gamma$ genes [28]. In all three mutational spectra studies considered, mutants were derived from a subset of subjects and, in a small minority of cases, multiple clones were analyzed from the same individual. In the McGinness et al [29] and Manchester et al [21] studies molecular analyses consisted of Southern blotting with a full length human HPRT cDNA as probe. In the Finette et al [23] study, all but one mutant was defined more completely by sequencing of the base change(s) involved or of the deletion breakpoints.

\section{Results and discussion Study I}

The first set of data was derived from a cohort of 70 newborns born at two hospitals in Denver, Colorado [21]. HPRT $\mathrm{M}_{f}$ were determined on cord blood samples using the clonogenic assay. Smoking status was initially separated into three categories: active smokers, active smokers who quit after confirmation of pregnancy (quitters), and non-smokers. In a secondary analysis, non-smokers were then broken out into those likely to have ongoing exposure to environmental tobacco smoke and those actively avoiding passive or secondary smoking exposure. These categories were based on the paradigm that the genotoxic effects of secondary smoke should be intermediate between those of non-smokers with no secondary exposure and active smokers, and their exposure levels and therefore induced mutation frequencies were expected to be closer to those of the non-exposed population than those of the active smokers. Thus, the HPRT $\mathrm{M}_{f}$ of the total non-smoking population (with and without evidence of passive exposure, although clearly skewed towards the passively exposed population, which contributed 20 of the 28 subjects in this category) was used as the basis of comparison for the smoking and quitting groups, and neither was found to have a significant induction of HPRT mutants. In the present investigation, we have combined these primary and secondary analyses, using only the nonsmokers with no evidence of secondary tobacco smoke exposure as the basis of comparison (this was the only category in the original study reported as having a significantly lower $\mathrm{M}_{f}$ ). These data are summarized in Table 1, panel $a$.

One outlier was identified in this data set, defined as an individual with an HPRT $\mathrm{M}_{f}$ greater than 3 standard deviations higher than the mean for the population. This individual was born to a women who quit smoking during her pregnancy, and had an $\mathrm{M}_{f}$ of $14.7 \times 10^{-6}, 10$-fold higher than the mean of the entire population, 15-fold higher than the median value.

By breaking the "non-smoking" population into those with and without evidence of environmental tobacco smoke exposure, and using those with no evidence of such passive exposure as baseline, we now show both significant effects of tobacco smoke exposure overall in this population, as well as significant inductions in all three exposed categories. Moreover, the HPRT $\mathrm{M}_{f}$ in the three exposed populations were not significantly different from one another (pairwise $P$ values ranged from 0.09 to 0.75 ), unless the outlier was included in the analysis, in which case the "quitters" were significantly higher than all three of the other groups. 
Table I: HPRT $M_{f}$ in newborns with and without exposure to tobacco smoke metabolites in utero

\begin{tabular}{|c|c|c|c|c|c|c|}
\hline & & & HPRT M & & & \\
\hline maternal exposure & $\mathrm{N}$ & mean $\pm S D$ & median & range & $\mathrm{Pl}^{1,2}$ & $\mathrm{P}^{2,3}$ \\
\hline a) data from Manchester & & & & & & \\
\hline unexposed & 18 & $0.76 \pm 0.50$ & 0.61 & $0.14-1.9$ & & \\
\hline passive only & 20 & $1.60 \pm 1.43$ & 1.35 & $0.30-5.3$ & 0.021 & \\
\hline quit during pregnancy ${ }^{4}$ & 4 & $1.85 \pm 1.16$ & 1.60 & $0.35-3.2$ & 0.004 & \\
\hline smoked throughout & 27 & $1.36 \pm 0.99$ & 0.98 & $0.28-3.5$ & 0.019 & 0.012 \\
\hline b) data from Finette et al & & & & & & \\
\hline unexposed & 26 & $0.72 \pm 0.53$ & 0.52 & $0.05-1.9$ & & \\
\hline passive only ${ }^{5}$ & 22 & $1.18 \pm 1.28$ & 0.67 & $0.10-5.1$ & 0.14 & \\
\hline quit during pregnancy & 8 & $0.79 \pm 0.46$ & 0.69 & $0.18-1.8$ & 0.51 & \\
\hline smoked throughout & 12 & $0.71 \pm 0.51$ & 0.56 & $0.14-1.8$ & 0.73 & 0.47 \\
\hline c) pooled data & & & & & & \\
\hline unexposed & 44 & $0.73 \pm 0.51$ & 0.60 & $0.05-1.9$ & & \\
\hline passive only ${ }^{5}$ & 42 & $1.38 \pm 1.36$ & 0.87 & $0.10-5.3$ & 0.006 & \\
\hline quit during pregnancy ${ }^{4}$ & 12 & $1.27 \pm 0.93$ & 0.91 & $0.18-3.2$ & 0.014 & \\
\hline smoked throughout & 39 & $1.16 \pm 0.91$ & 0.87 & $0.14-3.5$ & 0.007 & 0.007 \\
\hline
\end{tabular}

'specific exposed group vs. unexposed HPRT M from single factor ANOVA on In transformed data

2 since these four tests were performed simultaneously, to preserve an overall $\alpha$ of 0.05 , the threshold for significance of each individual test should be set at $P=0.0125$, or, if exposure is only tested for an induction of mutation, $P=0.025$

${ }^{3}$ overall single factor ANOVA on In transformed data

${ }^{4}$ excluding outlier with HPRT $\mathrm{M}_{f}$ of $14.7 \times 10^{-6}$

5 excluding outlier with HPRT $\mathrm{M}_{f}$ of $45.3 \times 10^{-6}$

\section{Study 2}

The second set of data is derived from two related publications [22,23], that were designed as follow-ups to those of McGinniss et al [11] and Manchester et al [21]. In the former study, newborns in Burlington, Vermont, demonstrated no detectable effect of maternal active smoking on cord blood HPRT $\mathrm{M}_{f}$, although passive exposure was not considered, and therefore might have been a confounding factor. Subjects for the follow-up studies were recruited from the same university-affiliated hospital in Vermont, and had similar HPRT $\mathrm{M}_{f}$. In this study, passive exposure was assessed by interview and ongoing tobacco smoke exposure was estimated by measurement of cotinine levels in the cord blood. In general, these cotinine measurements confirmed the smoking exposure assignments based on the interviews. These data are summarized in Table 1, panel $b$.

This population also contained an outlier, this one in the passively exposed group, with an $\mathrm{M}_{f}$ of $45.3 \times 10^{-6}$, 30-fold higher than the average of the population and 70 -fold higher than the median value.

Finette et al $[22,23]$ reported on two different but overlapping subsets of these data, and found no evidence of any type of tobacco smoke exposure affecting HPRT $\mathrm{M}_{f}$. Analysis of the entire data set, as summarized in Table 1, panel $b$, confirms these results. Indeed, only if the extreme outlier is included in the analysis is any comparison even close to significant (unexposed vs. passively exposed, $P=$ 0.063 ).

\section{Pooled data}

These two studies examined similarly sized populations, and both failed initially to demonstrate an influence of tobacco smoke exposure on newborn HPRT $\mathrm{M}_{f}$. These two sets of subjects are geographically distinct, and may differ in other ways, but this cannot be assessed from the published data. No other factor was reported to have significantly affected newborn HPRT $\mathrm{M}_{f}$ in either study, however. The $\mathrm{M}_{f}$ of the unexposed populations from the two studies are not significantly different from one another $(P=0.48)$, but the combined exposed population from the Colorado population is 1.5-fold higher than the equivalent population from the Vermont studies, which is significant $(\mathrm{P}<0.001)$. This difference has been attributed to maternal environmental and socioeconomic factors, but nothing has been proven. The distribution of samples between the four smoking exposure categories differs significantly between the two studies $(P=0.044)$, with the major disparity being the proportion of active smokers (39\% in the Manchester et al study [21] vs. $17 \%$ in the Finette et al studies [22,23], $P=0.006)$. It is tempting to invoke this difference in population distribution to 
explain the higher overall $\mathrm{M}_{f}$ of the Colorado population (mean $1.32 \times 10^{-6}$, median $0.96 \times 10^{-6}$, range $0.14-5.3 \times$ $10^{-6}$ ) than the population from Vermont (mean $0.89 \times 10^{-}$ 6 , median $0.64 \times 10^{-6}$, range $\left.0.05-5.1 \times 10^{-6}\right)(P=0.006)$ when the outliers are not included in the analysis. However, the proportion of all tobacco-exposed individuals (including active smokers, quitters and passively exposed mothers) is not significantly different between the two populations $(74 \%$ vs. $62 \%, P=0.66)$. The HPRT $\mathrm{M}_{f}$ for the pooled data set are given in Table 1, panel $c$.

Analysis of the pooled data from these two studies essentially reiterates the results of the reanalysis of the data from Manchester et al [21] discussed above: all three groups of tobacco exposed newborns have HPRT $\mathrm{M}_{f}$ significantly higher than the unexposed group, and there is no significant difference between the levels of induced mutation amongst the three exposed populations. These data indicate that tobacco smoke exposure in utero does induce detectable HPRT mutants in the fetus, and that passive maternal exposure has a similar teratogenic effect as active maternal smoking, a finding that is not unprecedented [30].

\section{HPRT molecular spectra}

Despite the lack of evidence for a mutagenic effect of tobacco smoke in their newborn cord bloods, Finette et al [23] nevertheless examined the molecular spectrum of HPRT mutants in two of their subpopulations, those without evidence of any maternal tobacco smoke exposure and those with passive exposure only. The mutations were classified as a) small, intragenic changes, b) gene rearrangements or deletions, or c) exon 2/3 deletions characteristic of illegitimate VDJ recombination (especially in newborn populations $[23,31,32])$. These data, summarized in Table 2, panel $a$, suggest a shift in the spectrum of the exposed population to significantly higher proportions of both small mutations and deletions attributable to VDJ recombination. Since there was no overall increase in HPRT $\mathrm{M}_{f}$ in this population, however, the exposed population also had a compensatory significantly lower proportion of non-VDJ mediated deletions and rearrangements, suggesting a protective effect of tobacco smoke exposure on these types of mutagenic events. We have found that the need to invoke such a protective effect is reduced if these data are put in perspective of the related studies mentioned above [21,23] and if mutation frequencies are used to normalize the distributions.

Table 2: HPRT mutational spectra in newborns with and without exposure to tobacco smoke metabolites in utero

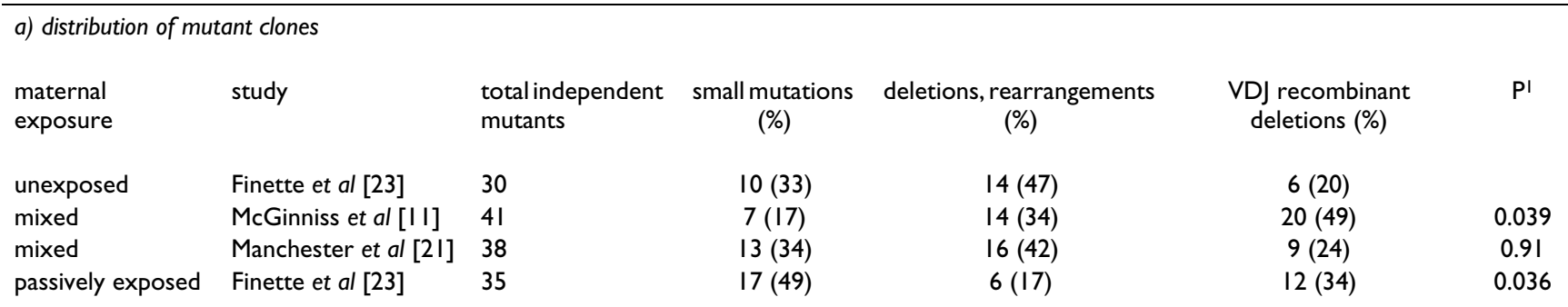

b) mutation frequencies for three classes of mutants based on individual studies

$\begin{array}{lllccr}\begin{array}{l}\text { maternal } \\ \text { exposure }\end{array} & \text { study } & \begin{array}{l}\text { overall mean } \\ M_{f} \pm S D\left(\times 10^{-6}\right)\end{array} & \begin{array}{c}\text { small mutations } \\ M_{f}\left(\times 10^{-6}\right)\end{array} & \begin{array}{c}\text { deletions, rearrangements } \\ M_{f}\left(\times 10^{-6}\right)\end{array} & \begin{array}{c}\text { VDJ recombinant } \\ \text { deletions } M_{f}\left(\times 10^{-6}\right)\end{array} \\ \text { unexposed } & \text { Finette et al }[22,23] & 0.72 \pm 0.53 & 0.24 & 0.34 & 0.14 \\ \text { mixed } & \text { McGinniss et al }[11] & 0.64 \pm 0.40 & 0.11 & 0.22 & 0.31 \\ \text { mixed } & \text { Manchester et al }[21] & 1.32 \pm 1.093 & 0.45 & 0.56 & 0.31 \\ \text { passively exposed } & \text { Finette et al }[22,23] & 1.18 \pm 1.28^{4} & 0.57 & 0.20 & 0.003 \\ & & & & 0.40 & 0.001 \\ \end{array}$

c) mutation frequencies for three classes of mutants based on pooled data ${ }^{5}$

\begin{tabular}{lllllrr} 
unexposed & Finette et al $[22,23]$ & $0.73 \pm 0.51$ & 0.24 & 0.34 & 0.15 & 0.008 \\
mixed & McGinniss et al [II] & $0.99 \pm 0.95$ & 0.17 & 0.34 & 0.48 & 0.037 \\
mixed & Manchester et al [2I] & $0.99 \pm 0.95^{3}$ & 0.34 & 0.42 & 0.24 & 0.47 \\
passively exposed & Finette et al [22,23] & $1.38 \pm 1.36^{4}$ & 0.67 & 0.24 & $<0.001$ \\
\hline
\end{tabular}

${ }^{1} \chi^{2}$

$2_{t}$ tests on In transformed data

3excluding outlier with HPRT $\mathrm{M}_{f}$ of $14.7 \times 10^{-6}$

${ }^{4}$ excluding outlier with HPRT $M_{f}$ of $45.3 \times 10^{-6}$

5 for the purposes of this analysis the data of McGinniss et al [II] was pooled with that of Manchester et al [2I] and Finette et al [22,23] to yield a single $M_{f}$ 
Summaries of the HPRT mutational spectra generated from the earlier analysis of a newborn population from Vermont [29] and the Colorado UHD population [21] are also presented in Table $2 a$. These spectra were generated from mutants without regard for their potential tobacco smoke exposure, so are classified as "mixed". The population of McGinniss et al $[11,29]$ contained only $20 \%$ active smokers, however, while the incidence of passive exposure of the remaining $80 \%$ of the population was not estimated. $45 \%$ of the population reported in Manchester et al [21] actively smoked throughout pregnancy, and another 33\% reported ongoing exposure to secondary tobacco smoke; only 13\% could be considered unexposed. These data might therefore be expected to begin to show the effects of both active cigarette smoking and passive secondary exposure on cord blood HPRT mutagenesis, although the power would not be as great as if they were derived only from defined exposed groups.

In adults, active tobacco smoke exposure has been found to increase the frequency and proportion of small base changes at the HPRT gene [33], consistent with the known mechanisms of tobacco smoke mutagens and the types of mutations found in oncogenes in smoking-associated cancers [34,35]. Illegitimate VDJ recombination is a mechanism of mutagenesis unique to T- and B-lymphocytes, and is implicated in many of the molecular events associated with leukemia and lymphoma [36,37]. The human HPRT gene contains cryptic sites for this DNA splicing event, resulting in the deletion of exons 2 and 3 $[31,38]$, and the occurrence of this type of HPRT mutation seems to be associated with the incidence of acute lymphocytic leukemia in children [39]. Elevated levels of illegitimate VDJ recombination have been found in workers occupationally exposed to pesticides and herbicides [40], especially 2,4-dichlorophenoxyacetic acid $[41,42]$ and in cancer patients undergoing chemotherapy [43], particularly with the DNA topoisomerase inhibiting agent etoposide $[44,45]$.

Overall, the two newborn populations from Vermont had indistinguishable HPRT $\mathrm{M}_{f}(P=0.50)$, and the total population data from McGinniss et al [11] was also consistent with the unexposed group reported by Finette et al $[22,23]$ $(P=0.51)$, but the passively exposed group had a significantly higher level of mutation $(P=0.013)$. The distribution of mutants among the three mechanistic classes differed significantly in both cases, however, with the mutants from McGinniss et al [29] exhibiting less small mutation and more VDJ recombination-mediated deletion than either group from Finette et al $[22,23]$. The Colorado population had a significantly higher $\mathrm{M}_{f}$ than the unexposed subset of the second Vermont population $(P=0.008)$, but a very similar distribution of mutants $(P$ $=0.91)$. On the other hand, the Colorado population had a similar mutation frequency as the passively exposed subpopulation from this study $(P=0.55)$, but a somewhat different mutant distribution $(P=0.068)$. We believe that these mutational comparisons are of little use unless both frequency and distribution are taken into account at the same time. In Table 2, panels $b$ and $c$, the overall HPRT $\mathrm{M}_{f}$ from these individual studies and subpopulations (panel $b$ ), or the $\mathrm{M}_{f}$ generated from our pooled analysis (panel $c$ ), are used to calculate the frequency of each type of mutant in each population, as was done in Manchester et al [21] and Finette et al [23].

Expressing the mutational classes as frequencies makes it easier to see the general trends in these studies and their inconsistencies. The frequency of VDJ recombinationmediated deletions is now increased in all exposed populations, and the results from the mixed tobacco smoke populations are consistent with an intermediate level of exposure (remember that even though these populations should contain maternal active smoking exposures, and quitters, the meta-analysis indicated that these should have induced $\mathrm{M}_{f}$ similar to the passively exposed population). The differences in the frequencies of non-VDJ recombination-mediated deletions and rearrangements are diminished under these circumstances. The increase in frequency of small mutations observed in the passively exposed population of Finette et al $[22,23]$ is difficult to rationalize with the low levels found in the McGinniss et al [29] study, however, the induction in the Manchester $e t$ al [21] population is again intermediate between those of the two subpopulations from Finette et al $[22,23]$. Significantly, none of the decreases observed in the frequencies of mutational subclasses from the unexposed population of Finette et al [23] were themselves statistically significant.

\section{Discussion}

Pooling data from studies applying similar techniques has been shown to be a useful method of investigating subtle effects in molecular epidemiology [46]. The present data was derived from a limited number of studies, however, and may contain unintended bias based on mutation detection methods, study design or uncontrolled confounders. Moreover, we stress that all of this data is based on mutation at a single locus, the X-linked HPRT gene, which may not be representative of the entire genome [5].

All cells in the embryo undergo periods of rapid differentiation and proliferation. It has long been postulated that rapidly growing cells are at increased risk of genotoxic damage; this idea is based on the hierarchy of tissues affected by ionizing radiation exposure, the response of tumors to genotoxic chemotherapy, and has been put forward as a way to rationalize hormonal carcinogenesis with the somatic mutational basis of cancer. While in utero 
exposures have been associated with later increases in cancer susceptibility, this research has mostly involved agents that interfere with the differentiation process [47], rather than classical mutagens [48].

\section{Conclusion}

This analysis demonstrates that, despite the conclusions of the original papers presenting the data, both active and passive tobacco smoke exposure in utero results in increased fetal mutation at the HPRT locus. The observed mutational induction by passive maternal tobacco smoke exposure clarifies the shift in the HPRT mutational spectrum previously reported [23], without requiring a complementary protective effect of tobacco smoke on certain types of mutation. The types of mutations observed are consistent with the known mechanisms of tobacco smoke mutagenesis, as well as the unique biochemistry of T-lymphocytes during in utero development. The establishment of these in utero tobacco smoke effects depended not only on the size of the pooled data set, but also on the judicious selection of a control group, and should abundantly demonstrate the long-term benefits of publishing data in a form that allows for such a re-analysis.

The observation that tobacco smoke mutational effects were not significantly ameliorated by quitting active smoking after the first trimester is troubling. It may well be consistent with the "all-or-none" quality of toxic exposures early in development, although it is doubtful that mutations arising by the mechanism of VDJ recombination-mediated deletion are possible at such an early stage of development. A more probable explanation for the persistent mutational induction observed in the quitters may involve continued passive exposure, since smoking mothers are far more likely to also be exposed to secondary smoke in the home [49]. This question should be directly addressed. We are presently analyzing data from another large set of newborns. In a preliminary report of the first third of this data maternal exposure to alcohol rather than tobacco was associated with higher HPRT $\mathrm{M}_{f}[50]$, although there was a shift in the mutational spectrum in the children of smoking mothers consistent with those described here [51].

Overall, these data suggest that further modification of residential and occupational exposures may be necessary to protect the developing fetus from tobacco smoke mutagenesis during pregnancy. If passive exposure does as much damage to the fetus as active smoking, it is imperative that workplace protection be offered to pregnant women, or better, to women who might or intend to become pregnant. This protection must also be provided in the home, where not only the mother, but any other smoking members of the household should be encouraged to quit for the duration of the pregnancy (or longer), or at least should not smoke in the presence of the pregnant woman.

\section{Abbreviations}

HPRT, hypoxanthine-guanine phosphoribosyltransferase; $\mathrm{M}_{f}$, mutation frequency.

\section{Competing interests}

The author declares that he has no competing interests.

\section{Authors' contributions}

This study was conceived and performed by SGG.

\section{Acknowledgements}

This study was supported by grants HD33016 and AD36422 from the National Institute of Child Health and Human Development and by a grant from the University of Pittsburgh Competitive Medical Research Fund. We are particularly indebted to the authors of Finette et al [22,23] for publishing their data in sufficient detail as to allow this reanalysis.

\section{References}

I. Phillips DH: Smoking-related DNA and protein adducts in human tissues. Carcinogenesis 2002, 23:1979-2004.

2. Pfeifer GP, Denissenko MF, Olivier M, Tretyakova N, Hecht SS, Hainaut $P$ : Tobacco smoke carcinogens, DNA damage and p53 mutations in smoking-associated cancers. Oncogene 2002, 2I:7435-745I.

3. IARC Working Group on the Evaluation of Carcinogenic Risks to Humans: Tobacco smoke and involuntary smoking. IARC Monogr Eval Carcinogen Risks Hum 2004, 83: I- I 438.

4. Grant SG: Molecular epidemiology of human cancer: biomarkers of genotoxic exposure and susceptibility. J Environ Pathol Toxicol Oncol 200I, 20:237-253.

5. Grant SG, Jensen RH: Use of hematopoietic cells and markers for the detection and quantitation of human in vivo somatic mutation. In Immunobiology of Transfusion Medicine Edited by: Garratty G. New York, Marcel Dekker; 1993:299-323.

6. Cole J, Skopek TR: Somatic mutant frequency, mutation rates and mutational spectra in the human population in vivo. Mutat Res 1994, 304:33-105.

7. Curry J, Karnaoukhova L, Guenette GC, Glickman BW: Influence of sex, smoking and age on human hprt mutation frequencies and spectra. Genetics 1999, 152:1065-1077.

8. Tompa A, Sápi E: Detection of 6-thioguanine resistance in human peripheral blood lymphocytes (PBL) of industrial workers and lung cancer patients. Mutat Res I989, 2 I 0:345-35 I

9. Sala-Trepat M, Cole J, Green MHL, Rigaud O, Vilcoq JR, Moustacchi $E$ : Genotoxic effects of radiotherapy and chemotherapy on the circulating lymphocytes of breast cancer patients. III: Measurement of mutant frequency to 6-thioguanine resistance. Mutagenesis 1990, 5:593-598.

10. Davies MJ, Lovell DP, Anderson D: Thioguanine-resistant mutant frequency in T-lymphocytes from a healthy human population. Mutat Res 1992, 265:165-171.

II. McGinniss MJ, Falta MT, Sullivan LM, Albertini RJ: In vivo hprt mutant frequencies in $\mathrm{T}$-cells of normal human newborns. Mutat Res 1990, 240: 117-126.

12. Ammenheuser MM, Berenson AB, Stiglich NJ, Whorton EB Jr, Ward JB Jr: Elevated frequencies of hprt mutant lymphocytes in cigarette-smoking mothers and their newborns. Mutat Res 1994 , 304:285-294.

13. Nilsen ST, Sagen N, Kim HC, Bergsjo P: Smoking, hemoglobin levels, and birth weights in normal pregnancies. Am J Obstet Gynecol 1984, I 48:752-758.

14. Moessinger AC: Mothers who smoke and the lungs of their offspring. Ann N Y Acad Sci 1989, 562:101-104.

I5. Blair PS, Fleming PJ, Bensley D, Smith I, Bacon C, Taylor E, Berry J, Golding J, Tripp J: Smoking and the sudden infant death syndrome: results from $1993-5$ case-control study for confiden- 
tial inquiry into stillbirths and deaths in infancy. BM] 1996, 313:195-198.

16. Habek D, Habek JC, Ivanisevic M, Djelmis J: Fetal tobacco syndrome and perinatal outcome. Fetal Diagn Ther 2002, |7:367-37|.

17. Beckman DA, Brent RL: Mechanisms of teratogenesis. Annu Rev Pharmacol Toxicol 1984, 24:483-500.

18. Anderson LM, Hecht SS, Dixon DE, Dove LF, Kovatch RM, Amin S, Hoffmann D, Rice JM: Evaluation of the transplacental tumorigenicity of the tobacco-specific carcinogen 4-(methylnitrosamino)-I-(3-pyridyl)-I-butanone in mice. Cancer Res 1989, 49:3770-3775

19. Coghlin J, Gann PH, Hammond SK, Skipper PL, Taghizadeh K, Paul M, Tannenbaum S: 4-Aminobiphenyl hemoglobin adducts in fetuses exposed to the tobacco smoke carcinogen in utero. J Natl Cancer Inst 1991, 83:274-280.

20. Finette BA, Sullivan LM, O'Neill JP, Nicklas JA, Vacek PM, Albertini RJ: Determination of hprt mutant frequencies in T-lymphocytes from a healthy pediatric population: statistical comparison between newborn, children and adult mutant frequencies, cloning efficiency and age. Mutat Res 1994, 308:223-231.

21. Manchester DK, Nicklas JA, O'Neill JP, Lippert MJ, Grant SG, Langlois RG, Moore DH 3rd, Jensen RH, Albertini RJ, Bigbee WL: Sensitivity of somatic mutations in human umbilical cord blood to maternal environments. Environ Mol Mutagen 1995, 26:203-2 I 2.

22. Finette BA, Poseno T, Vacek PM, Albertini RJ: The effects of maternal cigarette smoke exposure on somatic mutant frequencies at the HPRT locus in healthy newborns. Mutat Res 1997, 377: II5-123.

23. Finette BA, O'Neill JP, Vacek PM, Albertini RJ: Gene mutations with characteristic deletions in cord blood $\mathrm{T}$ lymphocytes associated with passive maternal exposure to tobacco smoke. Nature Med 1998, 4:II44-II5I.

24. O'Neill JP, McGinniss MJ, Berman JK, Sullivan LM, Nicklas JA, Albertini $\mathrm{RJ}$ : Refinement of a T-lymphocyte cloning assay to quantify in vivo thioguanine-resistant mutant frequency in humans. Mutagenesis 1987, 2:87-94.

25. Manchester DK, Jacoby EH: Sensitivity of human placental monooxygenase activity to maternal smoking. Clin Pharmacol Ther 1981, 30:687-692.

26. Manchester DK, Bowman ED, Parker NB, Caporaso NE, Weston A: Determinants of polycyclic aromatic hydrocarbon-DNA adducts in human placenta. Cancer Res 1992, 52:1499-1503.

27. Van Vunakis H, Gjika HB, Langone Jj: Radioimmunoassay for nicotine and cotinine. In Environmental Carcinogens: Methods of Analysis and Exposure Measurement Volume 9. Edited by: O'Neill IK, Brunnemann KD, Dodet B, Hoffmann D. Lyon: WHO/IARC; 1987:3 I 7-330.

28. Nicklas JA, O'Neill JP, Albertini RJ: Use of T-cell receptor gene probes to quantify the in vivo hprt mutations in human $\mathrm{T}$ lymphocytes. Mutat Res 1986, 173:67-72.

29. McGinniss MJ, Nicklas JA, Albertini RJ: Molecular analyses of in vivo hprt mutations in human T-lymphocytes. IV. Studies in newborns. Environ Mol Mutagen 1989, I 4:229-237.

30. Rubin DH, Krasilnikoff PA, Leventhal JM, Weile B, Berget A: Effect of passive smoking on birth-weight. Lancet I986, 8504:4 I5-4I7.

31. Fuscoe JC, Zimmerman LJ, Lippert MJ, Nicklas JA, O'Neill JP, Albertini $\mathrm{RJ}: \mathrm{V}(\mathrm{D})$ J recombinase-like activity mediates hprt gene deletion in human fetal T-lymphocytes. Cancer Res 1991, 5 I:600I-6005

32. Yoshioka M, O'Neill JP, Vacek PM, Finette BA: Gestational age and gender-specific in utero $V(D)$ J recombinase-mediated deletions. Cancer Res 2001, 61:3432-3438.

33. Hackman P, Hou S-M, Nyberg F, Pershagen G, Lambert B: Mutational spectra at the hypoxanthine-guanine phosphoribosyltransferase (HPRT) locus in T-lymphocytes of nonsmoking and smoking lung cancer patients. Mutat Res 2000, 468:45-6I.

34. DeMarini DM, Shelton ML, Levine JG: Mutation spectrum of cigarette smoke condensate in Salmonella: comparison to mutations in smoking-associated tumors. Carcinogenesis 1995 16:2535-2542.

35. Denissenko M, Pao A, Tang M-S, Pfeifer GP: Preferential formation of benzo[a]pyrene adducts at lung cancer mutational hotspots in p53. Science 1996, 274:430-432.

36. Alt FW, Blackwell TK, DePinho RA, Reth MG, Yancopoulos GD: Regulation of genome rearrangement events during lymphocyte differentiation. Immunol Rev 1986, 89:5-30.
37. Kirsch IR, Lista F: Lymphocyte-specific genomic instability and risk of lymphoid malignancy. Semin Immunol 1997, 9:207-2I 5.

38. Fuscoe JC, Vira LK, Collard DD, Moore MM: Quantification of hprt gene deletions mediated by illegitimate $V(D) J$ recombination in peripheral blood cells of humans. Environ Mol Mutagen 1997, 29:28-35

39. Finette BA, Poseno T, Albertini RJ: V(D)J recombinase-mediated HPRT mutations in peripheral blood lymphocytes of normal children. Cancer Res 1996, 56:|405-I4I 2.

40. Lipkowitz S, Garry VF, Kirsch IR: Interlocus V-J recombination measures genomic instability in agriculture workers at risk for lymphoid malignancies. Proc Natl Acad Sci USA 1992, 89:530I-5305.

4I. Garry VF, Tarone RE, Kirsch IR, Abdallah JM, Lombardi DP, Long LK, Burroughs BL, Barr DB, Kesner JS: Biomarker correlations of urinary 2,4-D levels in foresters: genomic instability and endocrine disruption. Environ Health Perspect 200I, 109:495-500.

42. Knapp GW, Setzer RW, Fuscoe JC: Quantitation of aberrant interlocus T-cell receptor rearrangements in mouse thymocytes and the effect of the herbicide 2,4-dichlorophenoxyacetic acid. Environ Mol Mutagen 2003, 42:37-43.

43. Abdallah JM, Lombardi DP, Kirsch IR: Genetic instability in patients with Hodgkin's disease undergoing chemotherapy. Clin Invest 1995, 96:2744-2747.

44. Chen CL, Fuscoe JC, Liu Q, Relling MV: Etoposide causes illegitimate $V(D)$ J recombination in human lymphoid leukemic cells. Blood 1996, 88:2210-2218.

45. Fuscoe JC, Knapp GW, Hanley NM, Setzer RW, Sandlund JT, Pui CH, Relling MV: The frequency of illegitimate $V(D) J$ recombinasemediated mutations in children treated with etoposide-containing antileukemic therapy. Mutat Res 1998, 419:107-121.

46. Le Marchand L, Guo C, Benhamou S, Bouchardy C, Cascorbi I, Clapper ML, Garte S, Haugen A, Ingelman-Sundberg M, Kihara M, Rannug A, Ryberg D, Stucker I, Sugimura H, Taioli E: Pooled analysis of the CYPIAI exon 7 polymorphism and lung cancer (United States). Cancer Causes Control 2003, 14:339-346.

47. Hatch EE, Palmer JR, Titus-Ernstoff L, Noller KL, Kaufman RH, Mittendorf R, Robboy SJ, Hyer M, Cowan CM, Adam E, Colton T, Hartge $\mathrm{P}$, Hoover RN: Cancer risk in women exposed to diethylstilbestrol in utero. JAMA 1998, 280:630-634.

48. Diwan BA, Riggs CW, Logsdon D, Haines DC, Olivero OA, Rice JM, Yuspa SH, Poirier MC, Anderson LM: Multiorgan transplacental and neonatal carcinogenicity of 3'-azido-3'-deoxythymidine in mice. Toxicol Appl Pharmacol 1999, 161:82-99.

49. Hruba D, Kachlik P: Influence of maternal active and passive smoking during pregnancy on birthweight in newborns. Cent Eur J Public Health 2000, 8:249-252.

50. Bigbee WL, Day RD, Grant SG, Keohavong P, Xi L, Zhang L, Ness RB Impact of maternal lifestyle factors on newborn HPRT mutant frequencies and molecular spectrum - initial results from the Prenatal Exposures and Preeclampsia Prevention (PEPP) Study. Mutat Res 1999, 431:279-289.

51. Keohavong P, Xi L, Day RD, Zhang L, Grant SG, Day BW, Ness RB, Bigbee WL: HPRT gene alterations in umbilical cord blood Tlymphocytes in newborns of mothers exposed to tobacco smoke during pregnancy. Mutat Res 2005, 572:156-166.

\section{Pre-publication history}

The pre-publication history for this paper can be accessed here:

http://www.biomedcentral.com/1471-2431/5/20/prepub 